\title{
Sexting, Web-Based Risks, and Safety in Two Representative National Samples of Young Australians: Prevalence, Perspectives, and Predictors
}

Alyssa C Milton, BSc, MAppSc, PhD; Benjamin A Gill, BSc (Hons), BEng (Hons); Tracey A Davenport, BA (Hons), eMBA; Mitchell Dowling, BA/BAppPsych, BScPsych (Hons), PhD; Jane M Burns, BA (Hons), PhD; Ian B Hickie, AM, MD, FRANZCP, FASSA

Brain and Mind Centre, University of Sydney, Camperdown, Australia

\section{Corresponding Author:}

Alyssa C Milton, BSc, MAppSc, PhD

Brain and Mind Centre

University of Sydney

88 Mallet Street

Camperdown, 2050

Australia

Phone: 61286276947

Email: alyssa.milton@sydney.edu.au

\section{Abstract}

Background: The rapid uptake of information and communication technology (ICT) over the past decade—particularly the smartphone-has coincided with large increases in sexting. All previous Australian studies examining the prevalence of sexting activities in young people have relied on convenience or self-selected samples. Concurrently, there have been recent calls to undertake more in-depth research on the relationship between mental health problems, suicidal thoughts and behaviors, and sexting. How sexters (including those who receive, send, and two-way sext) and nonsexters apply ICT safety skills warrants further research.

Objective: This study aimed to extend the Australian sexting literature by measuring (1) changes in the frequency of young people's sexting activities from 2012 to 2014; (2) young people's beliefs about sexting; (3) association of demographics, mental health and well-being items, and internet use with sexting; and (4) the relationship between sexting and ICT safety skills.

Methods: Computer-assisted telephone interviewing using random digit dialing was used in two Young and Well National Surveys conducted in 2012 and 2014. The participants included representative and random samples of 1400 young people aged 16 to 25 years.

Results: From 2012 to 2014, two-way sexting (2012: 521/1369, 38.06\%; 2014: 591/1400, 42.21\%; $P=.03$ ) and receiving sexts (2012: 375/1369, 27.39\%; 2014: 433/1400, 30.93\%; $P<.001)$ increased significantly, not sexting (2012: 438/1369, 31.99\%; 2014: $356 / 1400,25.43 \% ; P<.001)$ reduced significantly, whereas sending sexts $(2012: \mathrm{n}=35 / 1369,2.56 \% ; 2014: \mathrm{n}=20 / 1400,1.43 \%$; $P>.05$ ) did not significantly change. In addition, two-way sexting and sending sexts were found to be associated with demographics (male, second language, and being in a relationship), mental health and well-being items (suicidal thoughts and behaviors and body image concerns), and ICT risks (cyberbullying others and late-night internet use). Receiving sexts was significantly associated with demographics (being male and not living with parents or guardians) and ICT risks (being cyberbullied and late-night internet use). Contrary to nonsexters, Pearson correlations demonstrated that all sexting groups (two-way, sending, and receiving) had a negative relationship with endorsing the ICT safety items relating to being careful when using the Web and not giving out personal details.

Conclusions: Our research demonstrates that most young Australians are sexting or exposed to sexting in some capacity. Sexting is associated with some negative health and well-being outcomes-specifically, sending sexts is linked to suicidal thoughts and behaviors, body image issues, and ICT safety risks, including cyberbullying and late-night internet use. Those who do sext are less likely to engage in many preventative ICT safety behaviors. How the community works in partnership with young people to address this needs to be a multifaceted approach, where sexting is positioned within a wider proactive conversation about gender, culture, psychosocial health, and respecting and caring for each other when on the Web. 
(JMIR Ment Health 2019;6(6):e13338) doi: 10.2196/13338

\section{KEYWORDS}

youth; sexual behavior; cyberbullying; mental health; internet; safety; risk

\section{Introduction}

\section{Background}

In recent decades, the increasing number of young people engaging in sexting has become a highly publicized and controversial part of the information and communication technology (ICT) transformation [1]. Although the definition of sexting varies, it refers to the sending, receiving, or forwarding of sexually explicit images, videos, or messages [2]. Sexting may represent a normal expression of sexuality among young people [3], with some researchers highlighting that sexting may be "the new first base" [4]. Despite this, it attracts concern from parents, teachers, policy makers, and organizations working with young people [5]. This concern often stems from sexting being linked to legal consequences [6,7] when legal sexting provisions for minors do not apply [8] —as well as negative social, emotional, and mental health effects [1]. Given the likely relationship between sexting and mental health problems, comprehensive research using random and representative national samples is needed to improve our understanding of the prevalence, beliefs, and associations of sexting to inform support practices and educational efforts targeting young people. In addition, outcomes of such research may help to inform mental health prevention and early intervention efforts targeted at young people, which are key priorities for the Australian government [9] and internationally [10].

\section{Sexting Prevalence}

International research has primarily focused on sexting prevalence among adolescents and young adults; however, this has yielded broad variability in results. Recent systematic review evidence suggests that internationally, only a minority of young people engage in sexting-with an average of 1 in 7 sending sexts and 1 in 4 receiving sexts (which varies by age, reporting year, and method of sexting) [2]. Within the Australian context, the prevalence estimates are higher and remain variable, particularly for those who have received sexts. Specifically, $43 \%$ to $49 \%$ of young people report sending sexts, $42 \%$ to $67 \%$ report that they have received sexts, and $40 \%$ to $46 \%$ report having sent or received sexts $[6,7,11,12]$. Variability in results is at least partially attributed to inconsistencies in sampling techniques [1,13]. For example, all previous Australian studies reporting prevalence have employed convenience or self-selected sampling techniques. Research that applies nationally representative and random sampling survey techniques is clearly needed.

Variability in prevalence rates has been partially explained by inconsistencies in definitions and measurement of sexting behaviors $[1,13,14]$. Previous Australian research has measured the lifetime experience of sexting, as opposed to sexting frequency over a specific period. This measurement approach poses challenges when comparing adolescent with young adult sexting prevalence, as young adults will have had more opportunities to engage in sexting. Another common issue when considering sexting prevalence in Australia is that measures of sending and receiving sexts have frequently been presented as 1 sexting variable. This creates challenges in comparing sexting prevalence and correlates between studies, either nationally or internationally. Addressing these issues relating to the operationalization and measurement of sexting warrants focus.

\section{Sexting Predictors and Correlates}

Multiple sociodemographic, mental health, and well-being variables have been implicated in the sexting literature [1]. Systematic review evidence suggests that compared with children and adolescents, young adults have higher prevalence rates for sending and receiving sexts [1]. However, most findings relating to sociodemographics are inconsistent, with ethnicity, gender, sexual orientation, education level, and employment status all yielding mixed findings.

Mental health and well-being variables and their association with sexting produce similar mixed findings. Sexting has been found to be associated with substance misuse [15], mental health problems [6], and suicidal thoughts and behaviors [16]. However, other studies report no associations between sexting and depression, anxiety, self-esteem [17], or mental health problems $[18,19]$. Poorer biopsychosocial well-being in young people results from sexting in combination with cyberbullying [20]. Moreover, young people who engage in sexting are more likely to not only experience cyber victimization but also to be victimized by different types of cyber victimization [21]. Despite the number of individual studies looking at sexting and its correlates, in the Australian context, there is a distinct need for a comprehensive examination of the associations between different types of sexting — such as sending, receiving, two-way, and not sexting — and other factors including a young person's sociodemographics, mental health and well-being, and other ICT risk behaviors such as cyberbullying.

\section{Sexting and Information and Communication Technology Use}

Research examining technology use and sexting has reported associations between sexting and time spent texting [16], problematic smartphone use [22], having a Facebook account, and Web-based video chatting with strangers [23]—but not hours spent on the internet daily [17]. Sexting predominately occurs through smartphone apps, such as Snap Inc."s Snapchat-with these apps being perceived by participants as a more "...convenient, safe, and informal means of sexting communication than other mediums, such as e-mail or Facebook, regardless of the actual risk of unauthorized distribution" [24]. How young Australians practice ICT safety when using such technologies and forming an understanding of how ICT safety practices relate to different types of sexting behaviors (ie, sending, receiving, two-way, and not sexting) has not, to our knowledge, been researched. 


\section{This Research}

This study extends the Australian literature to provide sexting prevalence and correlates among young Australians using the results from the 2012 and 2014 Young and Well National Surveys, which include representative and random samples of 1400 young people aged 16 to 25 years. This research directly addressed the research gaps within the Australian context, including the reliance on convenience or self-selected samples, and the lack of comprehensive reporting on the relationship between sexting and other factors such as sociodemographics, mental health and well-being items, and ICT risks and ICT safety practices.

This study has 4 main aims, including the assessment of (1) the changes in the frequency of young people's sexting activities from 2012 to 2014; (2) young people's beliefs about sexting; (3) the association of demographics, health and well-being items, and internet use with sexting activity; and (4) the relationship between sexting and ICT safety skills.

\section{Methods}

\section{Participants and Recruitment}

This study received ethics approval from The University of Sydney human research ethics committee (2012 Protocol No. 2012/1640; 2014 Protocol No. 2014/741) and was a partnership between the authors who were associated with the Young and Well Cooperative Research Centre (CRC; 2011-16) and The University of Sydney's Brain and Mind Centre (BMC). The survey was run using computer-assisted telephone interviewing (CATI). These telephone interviews were conducted by an independently contracted company - the Social Research Centre (Melbourne, Victoria) - that was commissioned by the authors to run the CATI. Respondents were randomly selected using random digit dialing (RDD) and included 700 young men and 700 young women aged 16 to 25 years. RDD has been cited as the historical gold standard for population-based control recruitment when conducting epidemiologic research [25]. Stratification was used to ensure that the samples were representative of the general population in terms of age, gender, and geographic location across all Australian states and territories. Participation was voluntary, and verbal consent was obtained at the start of the telephone interview. The respondents were excluded if they had English language difficulties or if they were uncomfortable with the interview being conducted in English. For all respondents aged 16 or 17 years, consent from a coresident parent or guardian was sought in addition to the young person's consent before the commencement of the survey. Research was conducted in accordance with the Social Research Centre's code of practice, and the survey took approximately $20 \mathrm{~min}$ to complete.

\section{Questionnaire}

The first and second Young and Well National Surveys (2012 and 2014) included questions relating to demographics, mental health and well-being, health perceptions of Australian youth, use of the internet, Web-based and communication risks (digital abuse such as bullying and sexting), digital literacy, and ICT safety skills.
Mental health and well-being survey items included the following: (1) the Kessler Psychological Distress Scale [26] assessing psychological distress during the past month; (2) the Psychiatric Frequency Symptom Scale (suicidality subscale) [27] measuring suicidal thoughts and behaviors; (3) experience of a mental health diagnosis and an alcohol or other substance use problem were measured with 2 single items asking an individual's desire to cut back and social/professional encouragement to stop; (4) issues of personal concern items included alcohol, body image, bullying or emotional abuse, coping with stress, depression, drugs, and self-harm; (5) resilience was measured by the Brief Resilience Coping Scale [28]; and (6) perceived social support and conflict in close relationships were measured in the 2014 survey only by the Social Support and Conflict Scale [29].

Internet use was based on survey items used in the headspace National Youth and Parent Community Survey [30]. Items of interest included (1) average time spent on the internet and (2) late-night internet use after $11 \mathrm{pm}$. Furthermore, respondents were asked about "Internet rules that some people follow" (2012 National Survey only) and personal experience of applying ICT safety (2014 National Survey only). Web-based and communication risks items were developed by the research group based on the reviews of national and international literature. To determine sexting beliefs and behaviors, respondents were asked (1) whether they considered sexting a serious problem for young people, (2) whether they had seen or received images or messages of a sexual nature in the previous 12 months, (3) whether they had sent messages or images of a sexual nature in the last 12 months, and (4) reasons for sexting and beliefs about sexting adapted from the study by Henderson [31] (2012 National Survey only). For the cyberbullying component, participants were asked (1) whether they considered sexting a serious problem for young people, (2) the frequency for which they had been cyberbullied in the previous 12 months, and (3) the frequency for which they had cyberbullied others in the previous 12 months.

\section{Analysis}

Data were analyzed using SPSS 22.0 for Windows [32]. Univariate descriptive and frequency statistics were used to describe all demographic, clinical, and internet use items. Chi-square analysis assessed changes in sexting activity rates from 2012 to 2014. Phi was used to determine the effect size. Frequency statistics were used to describe young people's beliefs about sexting. Binary logistic regression analyses were used to investigate possible predictors of sexting ( 2 way, sending, receiving, and no sexting), reported as adjusted odds ratios (AORs) at a $95 \%$ confidence interval (CI). Pearson bivariate correlations determined the relationship between sexting groups (2way, sending, receiving, and no sexting) and ICT safety items. No missing data were imputed for any analysis.

\section{Results}

\section{Sample Characteristics}

In both 2012 and 2014, half of the 1400 young people who participated were male (2012: 700/1400, 50.00\%; 2014: $705 / 1400,50.36 \%$ ). Approximately one-third of the respondents 
were from each target age group: 16 to 18 years (2012: $484 / 1400,34.57 \%$; 2014: 499/1400, 35.64\%), 19 to 21 years (2012: 466/1400, 33.28\%; 2014: 464/1400, 33.14\%), and 22 to 25 years (2012: 450/1400, 32.14\%; 2014: 437/1400, 31.21\%). In both surveys, the majority (2012: 1086/1400, 77.57\%; 2014: $1107 / 1400,79.07 \%$ ) of the respondents did not speak any language other than English. Rates of identification with Aboriginal or Torres Strait Islander descent (2012: 30/1400, $2.14 \%$; 2014: 48/1400, 3.43\%) were reflective of national census rates [33]. The majority of young people lived in major cities (2012: 1047/1400, 74.79\%; 2014: 1048/1400, 74.86\%) and lived with at least one of their parents or guardians (2012: 1031/1400, 73.64\% ; 2014: 1057/1400, 75.50\%). In addition, over half of them described education as their main current activity (2012: 869/1399, 58.18\%; 2014: 814/1398, 57.79\%) and one-third of respondents were employed in some capacity (2012: 493/1399, 35.24\%; 2014: 474/1398, 33.86\%). Changes in sociodemographics, mental health and well-being, and internet use between 2012 and 2014 are presented in Multimedia Appendix 1.

\section{Sexting Prevalence}

Young people's overall sexting activities from 2012 to 2014 changed significantly; a breakdown of these changes by type of sexting activity is presented in Table 1. From 2012 to 2014, young people most commonly endorsed being reciprocal two-way sexters (2012: 521/1369, 38.06\%; 2014: 591/1400, $42.21 \%)$, and this increased significantly from 2012 to 2014 $(P=.03)$. The number of young people reporting only receiving sexts increased significantly from 2012 to 2014 (2012: 375/1369, $27.39 \% ; 2014: 433 / 1400,30.93 \% ; P<.001)$, whereas those only sending sexts did not change significantly over time and was the least endorsed sexting behavior (2012: 35/1369, 2.56\%; 2014: 20/1400, 1.43\%). The proportion of young people reporting that they were a nonsexter reduced significantly from one-third to a quarter of respondents between 2012 and 2014 (2012: 438/1369, 31.99\%; 2014: 356/1400, 25.43\%; $P<.001)$.

A more detailed breakdown of the specific types of sexting activities that young people engaged in is presented in Table 2.

Table 1. Prevalence of sexting between 2012 and 2014.

\begin{tabular}{llllcc}
\hline Sexting category & Yes in 2012 (N=1369), n $(\%)$ & Yes in 2014 (N=1400), n $(\%)$ & Chi-square $(d f)$ & $P$ value & Phi \\
\hline Two-way sexting & $521(38.06)$ & $591(42.21)$ & $5.0(1)$ & .03 & .04 \\
Only sending sexts & $35(2.56)$ & $20(1.43)$ & $2.6(1)$ & .11 & -.03 \\
Only receiving sexts & $375(27.39)$ & $433(30.93)$ & $19.3(1)$ & $<.001$ \\
Nonsexter & $438(31.99)$ & $356(25.43)$ & $14.6(1)$ & $<.001$ \\
\hline
\end{tabular}

Table 2. Frequency of young people's sexting behaviors.

\begin{tabular}{|c|c|c|c|c|c|}
\hline Sexting behavior & $\begin{array}{l}\text { Yes in } 2012 \\
(\mathrm{~N}=1369), \mathrm{n}(\%)\end{array}$ & $\begin{array}{l}\text { Yes in } 2014 \\
(\mathrm{~N}=1400), \mathrm{n}(\%)\end{array}$ & $\begin{array}{l}\text { Chi-square } \\
(d f)\end{array}$ & $P$ value & Phi \\
\hline \multicolumn{6}{|l|}{ Receiver $^{\mathbf{a}}$} \\
\hline Been sent sexual message & $552(40.32)$ & $644(46.00)$ & $9.1(1)$ & .003 & .057 \\
\hline Seen a sexual message posted where others could see it & $490(35.79)$ & $598(42.71)$ & $13.9(1)$ & $<.001$ & .104 \\
\hline Seen other people perform acts of a sexual nature & $361(26.37)$ & $540(38.57)$ & $47.0(1)$ & $<.001$ & .130 \\
\hline Been asked to talk about acts of a sexual nature with someone & $365(26.66)$ & $489(34.93)$ & $22.2(1)$ & $<.001$ & .089 \\
\hline Been asked for a photo or video showing yourself nude or nearly nude & $266(19.43)$ & $435(31.07)$ & $49.6(1)$ & $<.001$ & .134 \\
\hline None & $473(34.55)$ & $376(26.86)$ & $19.3(1)$ & $<.001$ & -.083 \\
\hline Refused & $1(0.07)$ & $4(0.29)$ & $1.7(1)$ & .19 & .025 \\
\hline \multicolumn{6}{|l|}{ Sender ${ }^{a}$} \\
\hline None & $813(59.39)$ & $789(56.36)$ & $2.6(1)$ & .11 & -.107 \\
\hline Talked about acts of a sexual nature with someone & $465(33.97)$ & $513(36.64)$ & $2.2(1)$ & .14 & .028 \\
\hline Sent someone a sexual message & $398(29.07)$ & $449(32.07)$ & $2.9(1)$ & .09 & .033 \\
\hline Sent someone a photo or video showing yourself nude or nearly nude & $140(10.23)$ & $237(16.93)$ & $26.4(1)$ & $<.001$ & .098 \\
\hline $\begin{array}{l}\text { Asked someone for a photo or video showing themselves nude or nearly } \\
\text { nude }\end{array}$ & $122(8.91)$ & $170(12.14)$ & $7.7(1)$ & .006 & .053 \\
\hline Posted a sexual message posted where others could see it & $41(2.99)$ & $24(1.71)$ & $5.0(1)$ & .03 & -.042 \\
\hline Refused & $2(0.15)$ & $8(0.57)$ & $3.5(1)$ & .06 & .062 \\
\hline
\end{tabular}

\footnotetext{
${ }^{\mathrm{a}}$ Arranged from most to least commonly endorsed item by receiver and by sender from the 2014 data.
} 
In both 2012 and 2014, when asked about the type of sexts being received, the most frequently reported item was being sent a sexual message (2012: 552/1369, 40.32\%; 2014: 644/1400, $46.00 \%$ ). Overall, the rates of endorsement of items relating to being a receiver of sexts increased significantly between 2012 and 2014 across all items, whereas endorsement of none fell significantly. Significant increases in endorsement rates between 2012 and 2014 for 4 items relating to the type of sexts being sent were found (sent someone a sexual message, sent someone a photo or video showing yourself nude or nearly nude, asked someone for a photo or video showing themselves nude or nearly nude, and posted a sexual message posted where others could see it). However, for all respondents, the most commonly endorsed item relating to sending sexts was none (2012: 813/1369, 59.39\%; 2014: 789/1400, 56.36\%).

\section{Beliefs About Sexting}

Consistently in both 2012 and 2014, over half (2012: 691/1369, $50.47 \%$; 2014: 707/1268, 50.50\%) of the respondents thought sexting was a serious problem for young people $\left(\chi^{2}=1.2 ; P=.27\right)$. The reasons for sexting and beliefs about sexting were explored in the 2012 survey and are presented in Table 3 and 4, respectively. The most commonly reported reason for sexting was "to get attention from a dating partner" (1217/1369, $88.90 \%)$. Sexting causing "serious negative consequences" was endorsed by nearly all respondents $(1263 / 1369,92.26 \%)$, and the vast majority believed that "messages usually end up being seen by more than just those to whom they were sent" $(1157 / 1369,84.51 \%)$.

\section{Sexting Predictors}

The associations between sexting activity and demographic, health and well-being items, and internet use were examined. AORs for the 2014 data are presented in Table 5. Additional crude risk ratios showing the strength of the relationships between each variable and sexting behavior are presented in Multimedia Appendix 2.

Table 3. Young people's reasons sexting in $2012(\mathrm{~N}=1369)$.

\begin{tabular}{ll}
\hline Item & Yes, $\mathrm{n}(\%)$ \\
\hline Reasons that young people send or post sexual material ${ }^{\mathbf{a}, \mathbf{b}}$ & $1217(88.90)$ \\
To get attention from a dating partner & $1111(81.15)$ \\
To be fun and flirtatious & $1093(79.84)$ \\
To be sexy or initiate sexual activity & $959(70.05)$ \\
They feel pressured to by friends or a dating partner & $677(49.45)$ \\
A form of self-expression & $22(1.61)$ \\
Don't know & $9(0.66)$ \\
Other reason & \\
\hline
\end{tabular}

${ }^{\mathrm{a}}$ Items not asked in 2014.

${ }^{\mathrm{b}}$ Arranged from most to least commonly endorsed item.

Table 4. Young people's beliefs about sexting in 2012 (N=1369).

\begin{tabular}{l}
\hline Item \\
\hline Beliefs about sexting ${ }^{\mathbf{a}, \mathbf{b}}$ \\
It can cause serious negative consequences \\
Messages usually end up being seen by more than just those to whom they were sent \\
Females have to worry about messages being viewed by someone other than the person they had originally intended 1067 (77.94) \\
it for, more than males do \\
There is pressure among young people to sext \\
Males have to worry about messages being viewed by someone other than the person they had originally intended $413(30.17)$ \\
it for, more than females do \\
It's no big deal
\end{tabular}

${ }^{\mathrm{a}}$ Items not asked in 2014.

${ }^{\mathrm{b}}$ Arranged from most to least commonly endorsed item. 
Table 5. Adjusted odds ratios of the association of demographics, health and well-being items, and internet use with sexting activity (2014; N=597).

\begin{tabular}{|c|c|c|c|c|}
\hline \multirow[t]{2}{*}{ Variable } & \multicolumn{4}{|c|}{ Sexting activity versus all others } \\
\hline & Two-way & Sender ${ }^{\mathrm{a}}$ & Receiver $^{\mathrm{b}}$ & No sexting \\
\hline \multicolumn{5}{|l|}{ Demographics } \\
\hline \multicolumn{5}{|c|}{ Gender (male vs female) } \\
\hline AOR $\operatorname{Exp}(B)^{c}$ & $0.63^{\mathrm{d}}$ & $0.58^{\mathrm{d}}$ & $0.59^{\mathrm{d}}$ & $1.73^{\mathrm{d}}$ \\
\hline $95 \% \mathrm{CI}^{\mathrm{e}}$ & $0.41-0.96$ & $0.38-0.89$ & $0.37-0.95$ & $1.07-2.80$ \\
\hline \multicolumn{5}{|c|}{ Age (16-18 years vs 19-21 years) } \\
\hline AOR Exp (B) & 1.13 & 1.11 & 0.83 & 1.22 \\
\hline $95 \% \mathrm{CI}$ & $0.71-1.80$ & $0.70-1.76$ & $0.51-1.37$ & $0.73-2.04$ \\
\hline \multicolumn{5}{|c|}{ Age (16-18 years vs 22-25 years) } \\
\hline AOR $\operatorname{Exp}(B)$ & 1.34 & 1.23 & 0.72 & 1.56 \\
\hline $95 \% \mathrm{CI}$ & $0.78-2.30$ & $0.72-2.10$ & $0.41-1.27$ & $0.87-2.79$ \\
\hline \multicolumn{5}{|c|}{ English only language spoken (no vs yes) } \\
\hline AOR $\operatorname{Exp}(B)$ & $1.66^{\mathrm{d}}$ & $1.71^{\mathrm{d}}$ & 1.53 & 0.62 \\
\hline $95 \% \mathrm{CI}$ & $1.01-2.73$ & $1.04-2.80$ & $0.93-2.55$ & $0.37-1.03$ \\
\hline \multicolumn{5}{|c|}{ Indigenous (no vs yes) } \\
\hline AOR $\operatorname{Exp}(B)$ & 0.74 & 0.93 & 0.93 & 0.7 \\
\hline $95 \% \mathrm{CI}$ & $0.23-2.37$ & $0.30-2.94$ & $0.23-3.80$ & $0.14-3.65$ \\
\hline \multicolumn{5}{|c|}{ Location (major city vs regional, rural, or remote) } \\
\hline AOR $\operatorname{Exp}(B)$ & 1.01 & 1 & 0.97 & 1.05 \\
\hline $95 \% \mathrm{CI}$ & $0.66-1.56$ & $0.65-1.54$ & $0.59-1.59$ & $0.63-1.74$ \\
\hline \multicolumn{5}{|c|}{ Currently in education (no vs yes) } \\
\hline AOR $\operatorname{Exp}(\mathrm{B})$ & 0.72 & 0.8 & 0.66 & 1.32 \\
\hline $95 \% \mathrm{CI}$ & $0.36-1.42$ & $0.41-1.59$ & $0.29-1.50$ & $0.58-3.02$ \\
\hline \multicolumn{5}{|c|}{ Currently in employment (no vs yes) } \\
\hline AOR $\operatorname{Exp}(B)$ & 1.36 & 1.57 & 1.05 & 0.76 \\
\hline $95 \% \mathrm{CI}$ & $0.68-2.74$ & $0.78-3.16$ & $0.45-2.45$ & $0.32-1.81$ \\
\hline \multicolumn{5}{|c|}{ Live with at least one parent or guardian (no vs yes) } \\
\hline AOR $\operatorname{Exp}(B)$ & 0.88 & 0.79 & $0.53^{\mathrm{d}}$ & $2.36^{\mathrm{f}}$ \\
\hline $95 \% \mathrm{CI}$ & $0.54-1.44$ & $0.48-1.28$ & $0.29-0.93$ & $1.28-4.36$ \\
\hline \multicolumn{5}{|c|}{ Currently in a relationship (no vs yes) } \\
\hline AOR $\operatorname{Exp}(B)$ & $2.16^{\mathrm{g}}$ & $2.11^{\mathrm{g}}$ & 1.14 & 0.9 \\
\hline $95 \% \mathrm{CI}$ & $1.47-3.19$ & $1.43-3.09$ & $0.73-1.76$ & $0.57-1.41$ \\
\hline \multicolumn{5}{|l|}{ Health and well-being } \\
\hline \multicolumn{5}{|c|}{ Psychological distress $\left(\mathrm{K}^{\mathrm{h}}{ }^{\mathrm{h}}\right.$ : low/moderate vs high/very high) } \\
\hline AOR $\operatorname{Exp}(B)$ & 0.68 & 0.67 & 1.36 & 0.72 \\
\hline $95 \% \mathrm{CI}$ & $0.39-1.17$ & $0.39-1.15$ & $0.74-2.49$ & $0.39-1.35$ \\
\hline \multicolumn{5}{|c|}{ Suicidal ideation and or acts (PSFS ${ }^{\mathbf{i}}$ ) } \\
\hline AOR $\operatorname{Exp}(\mathrm{B})$ & $1.86^{\mathrm{d}}$ & $2.21^{\mathrm{d}}$ & 1.1 & 0.63 \\
\hline $95 \% \mathrm{CI}$ & $1.00-3.46$ & $1.19-4.10$ & $0.53-2.33$ & $0.28-1.41$ \\
\hline
\end{tabular}




\begin{tabular}{|c|c|c|c|c|}
\hline \multirow[t]{2}{*}{ Variable } & \multicolumn{4}{|c|}{ Sexting activity versus all others } \\
\hline & Two-way & Sender ${ }^{\mathrm{a}}$ & Receiver $^{\mathrm{b}}$ & No sexting \\
\hline AOR $\operatorname{Exp}(B)$ & 0.92 & 0.93 & 1.68 & 0.57 \\
\hline $95 \% \mathrm{CI}$ & $0.57-1.51$ & $0.57-1.52$ & $0.96-2.96$ & $0.32-1.02$ \\
\hline \multicolumn{5}{|c|}{ Alcohol or other substance misuse diagnosis (no vs yes) } \\
\hline AOR $\operatorname{Exp}(B)$ & 3.74 & 3.34 & 0.72 & 1.96 \\
\hline $95 \% \mathrm{CI}$ & $0.38-36.96$ & $0.33-33.52$ & $0.07-7.76$ & $0.17-21.99$ \\
\hline \multicolumn{5}{|c|}{ Personal concern: Alcohol (no vs yes) } \\
\hline AOR $\operatorname{Exp}(B)$ & 1.04 & 1 & 1.04 & 1.02 \\
\hline $95 \% \mathrm{CI}$ & $0.58-1.87$ & $0.56-1.78$ & $0.51-2.11$ & $0.49-2.09$ \\
\hline \multicolumn{5}{|c|}{ Personal concern: Body Image (no vs yes) } \\
\hline AOR $\operatorname{Exp}(B)$ & $2.06^{\mathrm{f}}$ & $2.00^{\mathrm{f}}$ & 1.44 & 0.7 \\
\hline $95 \% \mathrm{CI}$ & $1.33-3.19$ & $1.30-3.08$ & $0.90-2.32$ & $0.43-1.14$ \\
\hline \multicolumn{5}{|c|}{ Personal concern: Bullying (no vs yes) } \\
\hline AOR $\operatorname{Exp}(B)$ & 1.37 & 1.16 & 0.85 & 1.53 \\
\hline $95 \% \mathrm{CI}$ & $0.80-2.34$ & $0.68-1.97$ & $0.46-1.58$ & $0.81-2.89$ \\
\hline \multicolumn{5}{|c|}{ Personal concern: Stress (no vs yes) } \\
\hline AOR $\operatorname{Exp}(B)$ & 1.11 & 1.16 & 1.26 & 0.75 \\
\hline $95 \% \mathrm{CI}$ & $0.71-1.73$ & $0.74-1.81$ & $0.78-2.04$ & $0.46-1.22$ \\
\hline \multicolumn{5}{|c|}{ Personal concern: Depression (no vs yes) } \\
\hline AOR $\operatorname{Exp}(\mathrm{B})$ & 0.63 & 0.68 & 0.62 & 1.56 \\
\hline $95 \% \mathrm{CI}$ & $0.35-1.12$ & $0.38-1.20$ & $0.33-1.16$ & $0.81-2.99$ \\
\hline \multicolumn{5}{|c|}{ Personal concern: Drugs (no vs yes) } \\
\hline AOR $\operatorname{Exp}(B)$ & 1.85 & 2 & 2.39 & $0.35^{\mathrm{d}}$ \\
\hline $95 \% \mathrm{CI}$ & $0.91-3.75$ & $0.99-4.05$ & $0.98-5.83$ & $0.14-0.90$ \\
\hline \multicolumn{5}{|c|}{ Personal concern: Self-harm (no vs yes) } \\
\hline AOR $\operatorname{Exp}(B)$ & 0.63 & 0.62 & 0.72 & 1.45 \\
\hline $95 \% \mathrm{CI}$ & $0.31-1.25$ & $0.31-1.24$ & $0.32-1.64$ & $0.61-3.43$ \\
\hline \multicolumn{5}{|l|}{ Resilience (BRCS ${ }^{\mathbf{j}}$ ) } \\
\hline AOR $\operatorname{Exp}(\mathrm{B})$ & 1.03 & 1.03 & 1.02 & 0.99 \\
\hline $95 \% \mathrm{CI}$ & $0.96-1.12$ & $0.95-1.11$ & $0.94-1.11$ & $0.90-1.08$ \\
\hline \multicolumn{5}{|c|}{ Social support $\left(\operatorname{SSCS}^{\mathrm{k}}\right)$} \\
\hline AOR $\operatorname{Exp}(B)$ & 0.96 & 0.96 & 1.03 & 0.97 \\
\hline $95 \% \mathrm{CI}$ & $0.88-1.04$ & $0.88-1.04$ & $0.93-1.13$ & $0.88-1.07$ \\
\hline \multicolumn{5}{|c|}{ Internet use and Web-based communication risks } \\
\hline \multicolumn{5}{|c|}{ Has been cyberbullied in the past 12 months (no vs yes) } \\
\hline AOR $\operatorname{Exp}(B)$ & 1.11 & 1.07 & $4.61^{\mathrm{f}}$ & $0.22^{\mathrm{f}}$ \\
\hline $95 \% \mathrm{CI}$ & $0.61-2.02$ & $0.59-2.94$ & $1.85-11.50$ & $0.09-0.56$ \\
\hline \multicolumn{5}{|c|}{ Cyberbullied others in the past 12 months (no vs yes) } \\
\hline AOR $\operatorname{Exp}(B)$ & $5.28^{\mathrm{g}}$ & $4.79^{\mathrm{g}}$ & 1.4 & 0.87 \\
\hline $95 \% \mathrm{CI}$ & $2.20-12.65$ & $2.00-11.44$ & $0.41-4.83$ & $0.25-3.02$ \\
\hline Average time spen & & & & \\
\hline
\end{tabular}




\begin{tabular}{|c|c|c|c|c|}
\hline \multirow[t]{2}{*}{ Variable } & \multicolumn{4}{|c|}{ Sexting activity versus all others } \\
\hline & Two-way & Sender ${ }^{\mathrm{a}}$ & Receiver $^{\mathrm{b}}$ & No sexting \\
\hline AOR $\operatorname{Exp}(B)$ & 1.02 & 1.02 & 0.98 & 1.02 \\
\hline $95 \% \mathrm{CI}$ & 0.96-1.09 & 0.96-1.09 & $0.92-1.05$ & $0.95-1.09$ \\
\hline \multicolumn{5}{|c|}{ Late-night internet use (no vs yes) } \\
\hline AOR $\operatorname{Exp}(B)$ & $1.92^{\mathrm{f}}$ & $1.88^{\mathrm{f}}$ & $2.58^{\mathrm{g}}$ & $0.38^{\mathrm{g}}$ \\
\hline $95 \% \mathrm{CI}$ & $1.24-2.95$ & $1.23-2.88$ & $1.67-3.98$ & $0.24-0.59$ \\
\hline
\end{tabular}

\footnotetext{
${ }^{\mathrm{a}}$ Includes all respondents who reported sending sexts in any form.

${ }^{\mathrm{b}}$ Includes all respondents who reported receiving sexts in any form.

${ }^{\mathrm{c}}$ AOR Exp (B): adjusted odds ratio exponentiation of the B coefficient.

${ }^{\mathrm{d}}$ Correlation is significant at the .05 level (2-tailed). Significant items are italicized in the table.

${ }^{\mathrm{e}} 95 \%$ Confidence Interval.

${ }^{\mathrm{f}}$ Correlation is significant at the .01 level (2-tailed). Significant items are italicized in the table.

${ }^{\mathrm{g}}$ Correlation is significant at $<.001$ (2-tailed). Significant items are italicized in the table.

${ }^{\mathrm{h}}$ Kessler psychological distress scale.

${ }^{i}$ Psychiatric Frequency Symptom Scale (suicidality subscale).

${ }^{\mathrm{j}}$ Brief Resilience Coping Scale.

${ }^{\mathrm{k}}$ Schuster's Social Support and Conflict Scale.
}

Two-way sexting and sending sexts yielded similar results. Specifically, being male (two-way: $P=.01$; sender: $P=.01$ ), speaking any language other than English (two-way: $P=.046$; sender: $P=.03$ ), being in a relationship (two-way: $P<.001$; sender: $P<.001$ ), experiencing suicidal thoughts and behaviors (two-way: $P=.048$; sender: $P=.012$ ), reporting body image concerns (two-way: $P=.001$; sender: $P=.002$ ), cyberbullying others (two-way: $P<.001$; sender: $P<.001$ ), and late-night internet use (two-way: $P=.003$; sender: $P=.004$ ) were associated with significantly greater AORs of both two-way sexting and sending sexts. Receiving sexts was significantly associated with being male $(P=.03)$, being cyberbullied $(P=.001)$, late-night internet use $(P<.001)$, and lower rates of living with parents or guardians $(P=.03)$.

Not sexting was significantly associated with being female $(P=.03)$ and living with parents or guardians $(P=.006)$ and lower rates of drugs being a personal concern $(P=.03)$, being cyberbullied $(P=.001)$, and late-night internet use $(P<.001)$.

\section{Sexting and Information and Communication Technology Safety Skills}

Sexting and its relationship with ICT safety items were measured with bivariate correlations. As presented in Table 6, all sexting activities (two-way, sending and receiving) had a significantly positive relationship with respondents "removing content they had posted online" $(P<.001)$ and "sharing particular kinds of information about themselves so that people won't ask them about their real feelings or desires" $(P<.001)$. All sexting activities (two-way $P<.001$, sending $P<.001$, and receiving $P=.002$ ) had a negative relationship with endorsing that people should not give out a personal address or phone number. Sending sexts $(P=.002)$ and two-way sexting $(P=.002)$ were negatively correlated with endorsing that people should keep their computer in a public room and being careful with what one posts online. Being a receiver of sexts demonstrated a strong positive correlation with reporting a person or incident to a site master $(P<.001)$ and ignoring threatening or offensive behavior toward both themselves $(P<.001)$ and others $(P=.003)$. Being a nonsexter was significantly negatively correlated with not posting because of future concerns $(P=.02)$, removing content $(P<.001)$, limiting information shared $(P=.009)$, reporting others $(P<.001)$, and ignoring threatening or offensive behavior toward themselves $(P<.001)$ or others $(P=.007)$. However, nonsexters were more likely to endorse not using a real name $(P=.04)$, not giving out an address or phone number $(P<.001)$, and being careful with what one should post online $(P=.009)$. 
Table 6. Bivariate correlations between sexting and information and communication technology safety items.

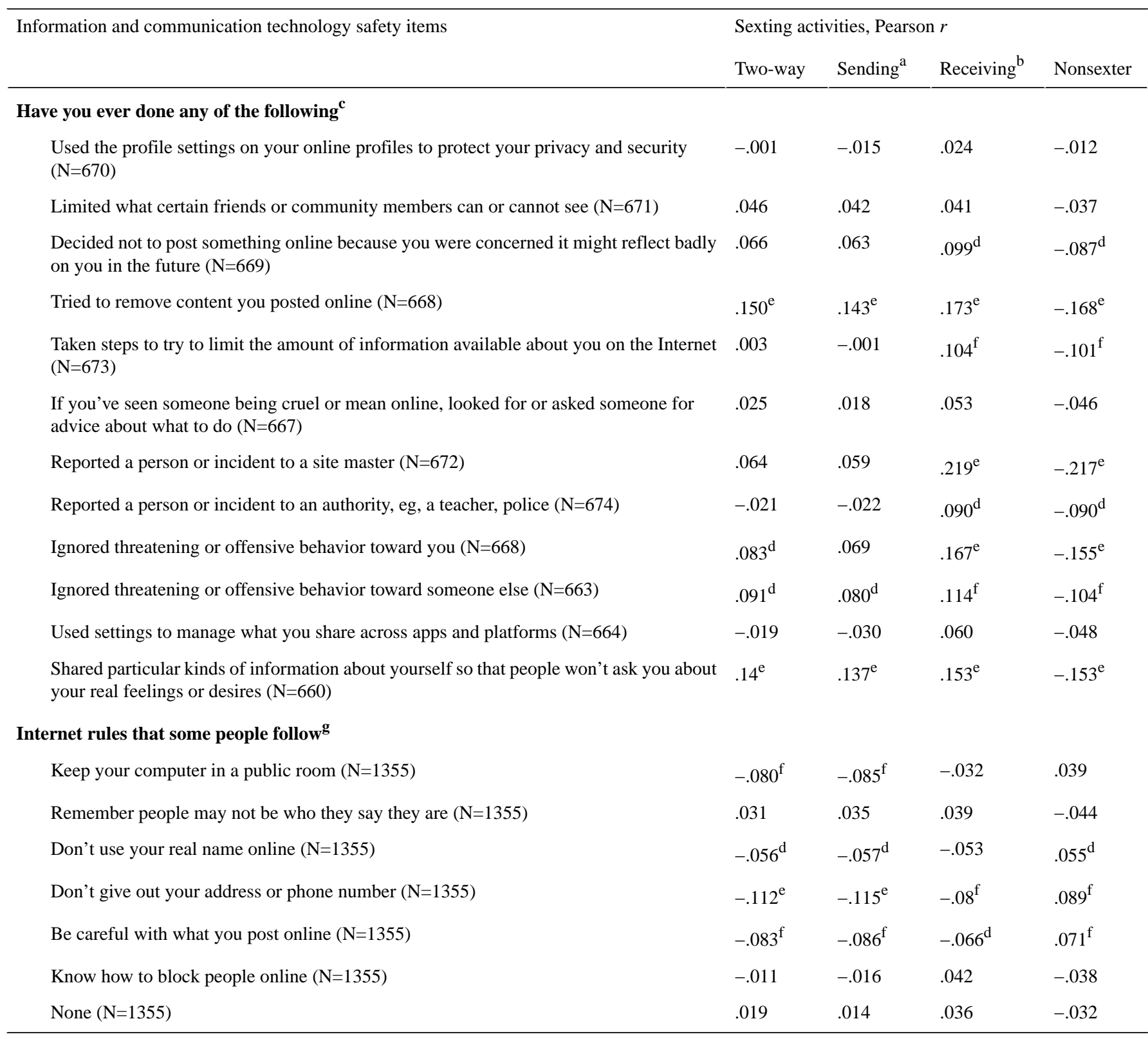

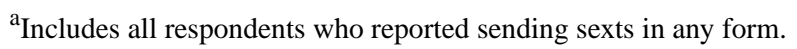

${ }^{\mathrm{b}}$ Includes all respondents who reported receiving sexts in any form.

$\mathrm{c}_{2014}$ data.

${ }^{\mathrm{d}}$ Correlation is significant at the .05 level ( 2 tailed).

${ }^{\mathrm{e}}$ Correlation <.001 (2 tailed).

${ }^{\mathrm{f}}$ Correlation is significant at the .01 level (2-tailed).

$\mathrm{g}_{2012 \text { data. }}$

\section{Discussion}

\section{Research Summary}

This is the first Australian study to examine sexting behaviors using 2 representative random samples of young people. The research presents changes in sexting prevalence, beliefs about sexting, predictors of sexting, and the application of ICT safety skills by young people who engage in different types of sexting activities. Importantly, the results are examined using 4 sexting categories to include nonsexters, receivers of sexts, senders of sexts, and two-way sexters, which is recommended as best practice when conceptualizing sexting [17].

\section{Sexting Prevalence}

The research found that from 2012 to 2014 , not engaging in any form of sexting reduced significantly from one-third to a quarter of respondents. Meaning that three-quarters of young Australians had recently engaged in, or been exposed to, some form of sexting activity by 2014 . This prevalence is high when compared with other Australian research using nonrepresentative or convenience samples $[6,7,11,12]$. 
By 2014, there was a significant increase in two-way sexting - with approximately 2 in 5 young people reporting that they had sent and received sexts. In the Australian sexting literature, this is the only known research to report on the prevalence of young people engaging in two-way sexting, so no direct comparisons can be made. When considering why so many young people are two-way sexting, research has reported that most young people share sexts within a dating relationship $[17,34]$. Therefore, it is possible that this finding reflects the reciprocal nature of sexting between sexual or presexual partners. Indeed, sexting today is increasingly viewed as a part of normal developmental behavior between young people [14,35].

Young people reporting only sending sexts remained minimal ( $<3 \%$ ) between 2012 and 2014, whereas those only receiving sexts significantly rose-with almost one-third of young people experiencing this by 2014. Although young people were not directly asked the reasons for only receiving sexts, it is possible that this rise reflects that more young people in 2014 were not reciprocating sexting despite being sent sexts intended for them. Another more widely reported explanation in the literature is that young people may have received photos that were originally intended for someone else (ie, the sext had been forwarded to them) [17].

\section{Sociodemographic Predictors of Sexting}

Previous research has predominately reported that young people in committed relationships are more likely to sext [34,36-38], whereas associations between gender and sexting have yielded mixed findings [16]. Some research examining interactions between both argue that relationship status, compared with gender, is significantly better at explaining interactions with sexting $[34,39]$. In this research, we examined 4 types of sexting activities and found that after adjusting for all variables, both gender and relationship status were associated with sexting. Specifically, two-way sexting, sending sexts, and receiving sexts were significantly associated with being male, whereas not sexting was associated with being female. In addition, two-way sexting and sending sexts were associated with relationship status. An explanatory reason for our findings can be drawn from previous sexting literature, which has reported that sexting can be socially riskier for certain individuals, such as females and those who are single [36]. These groups report stronger negative expectancies about sending and receiving sexts. Furthermore, the abovementioned secondhand sexting research has suggested that forwarded sexts can result in bullying or reputational damage of the individual who sent the original sext, particularly for young women [24,40-42], and young men are more likely to receive secondhand sexts [17]. This idea is further supported in our research findings that $78 \%$ of respondents believed that "females have to worry about messages being viewed by someone other than the person they had originally intended it for, more than males do," whereas only $30 \%$ of them endorsed the opposite viewpoint.

Individuals who spoke a second language had elevated odds of sending sexts and two-way sexting. Other research reports that being from a racial and ethnic minority is associated with sexting [16,43-45], although this may vary by the individual's ethnic background [46]. An additional finding from this study concerning the family composition was that young people who lived at home with their parents were less likely to receive sexts and more likely to be nonsexters, as compared with those who lived out of home. To our knowledge, this variable has not been previously researched [1]. However, the finding could be related to parental involvement-for example, parental restriction of mobile use has been previously found to be associated with lower sexting among young people [47]. Following this rationale, it is likely that those who live at home are more exposed to parental guidance and restrictions on their technology use and thus have less opportunity to sext.

\section{Health and Well-Being Predictors of Sexting}

In the literature, although the research is scant, sexting has been associated with a greater likelihood of contemplated or attempted suicide [16] and suicidal ideation [48]. In this study, after adjusting for multiple sociodemographic, health and well-being, and ICT risk behaviors, two-way sexting and sending sexts were significantly associated with reporting suicidal thoughts and behaviors in the past 12 months. This research is neither able to demonstrate a causal relationship among variables nor can it determine whether sexting is an antecedent or result of suicidal thoughts and behaviors. However, an explanatory rationale for this is that sexting is a risk behavior for young people [49,50]. Previous research, for example, has drawn significant links between sexual risk behaviors, such as unprotected sex, and suicidal ideation and behaviors [51,52]. Another possible explanation is that young people experiencing mental health issues may sext to feel wanted [16]. Conversely, other researchers have suggested that both the lack of control over a sext once it is sent and possible pressure to sext when in relationships may contribute to psychological distress [17]. Indeed, in this study, the vast majority of respondents thought young people sexted as they "feel pressured to by friends or a dating partner" and that "messages usually end up being seen by more than just those to whom they were sent."

Another well-being factor that the sexting literature has implicated is body image-with young people using sexting as a vehicle for obtaining feedback and reinforcing their body image [53,54]. This process of body image reinforcement has been cited as one of the major motivations for engaging in consensual sexting. However, research including body image concerns as a predictor of sexting is lacking. This research adds to the sexting literature by showing that body image concerns are a significant predictor of both two-way sexting and sending sexts. Some female-focused research has emphasized that sexual objectification of young women in general (ie, not digitally per se) is associated with depression, low self-esteem, eating distress, and negative body image $[55,56]$. This study suggests that body image may be a concern for both males and females who engage in 2two-way sexting and only sending sexts, as body image remained significant even after adjusting for all other variables including gender. Possible explanatory factors as to why young people with body image concerns have higher rates of sending sexts comes from research by Bianchi et al [54], who link young people with elevated body objectification with greater anxiety around sexuality and sexual intercourse. 
They argue that sexting may offer a way for these young people to experience sexuality despite their body-related concerns as it provides greater body image control, allows the sender to disengage emotionally, and be more assertive. Conversely, the same research acknowledges that body image-related motivations for sending sexts could expose a young person to suffer Web-based bullying and cyber victimization [54], which can exacerbate body image concerns.

\section{Information and Communication Technology Risk Predictors of Sexting}

Although late-night internet use is a key risk factor for problematic internet use [57], previous research has not to our knowledge examined its association with sexting. In this research, all types of sexting activity (two-way, sending and receiving) were significantly associated with late-night internet use. Scholars argue that the technology capabilities of the smartphone, which enable the selfie combined with late-night use, make it easier than ever for young people "to cross the line from selfie to sext" [58]. Similarly, cyberbullying has also been reported to peak in frequency during the evenings [59].

Previous research has reported that those who engaged in sexting were more likely to experience cyber victimization [21]. This study extends this literature as it demonstrates that even after adjusting for all variables, receiving a sext is associated with being cyberbullied, and two-way sexting and sending sexts is significantly associated with cyberbullying others-whereas being a nonsexter is associated with reduced odds of being cyberbullied. Generally, research suggests that sexting can transform into cyberbullying when the sext is shared by the receiver without the sender's consent [60]. In this study, it was the respondents who were more likely to be sending sexts (two-way and sending) that were engaging in cyberbullying. It is acknowledged that in this research, the survey did not distinguish between consensual sexting between intimate partners and nonconsensual sexting (such as sending secondhand sexts), which may influence the findings-particularly as relationship status predicted 2two-way sexting and sending sexts. Nevertheless, whether the sexts themselves form part of how respondents defined their cyberbullying experience is unknown, and further investigation is warranted-particularly given the link with serious concerns, including suicidal thoughts and behaviors.

\section{Sexting and Information and Communication Technology Safety Practices}

Young people in this study who are sexting (two-way, sending, and receiving) appear to engage in more post hoc ICT safety behaviors. For example, correlations demonstrated that respondents who sexted were more likely to have tried to remove content they had posted and ignore threatening or offensive behavior toward themselves or others. Young people who sexted (two-way, sending and receiving) were also less likely to endorse preventative ICT safety strategies, including being careful about what they post on the Web and protecting their identity by not providing others on the Web with their real name, address, and phone number. Interestingly, nonsexters were significantly less likely to engage in many of the ICT safety items personally but were more likely to endorse protecting their identity and being careful about what they post on the Web. This may suggest that nonsexters are exposing themselves less to risky behaviors on the Web and are thus less likely to need to personally protect themselves using ICT safety strategies. Whether this is because they have received better ICT safety education is unknown, but it does appear that their beliefs about protecting themselves when on the Web are more in line with ICT safety education practices, compared with those who do engage in sexting.

\section{Implications for Policy and Practice}

The research highlights the reality that there is a large proportion of young Australians sexting in some capacity. Although in Australia legal outcomes vary by state and territory and are addressed on a case-by-case basis [61], legal reforms in New South Wales have been implemented to reflect the view that sexting may be a normal part of sexual development and experimentation among many young people. Specifically, as a result of the Royal Commission into Institutional Responses to Child Sexual Abuse in 2018 [8], a legal exception has been introduced for children under 18 years who take, share, or possess nude photographs of themselves and others to minimize the risk of consenting children being convicted of possessing child pornography.

As sexting among young people is now more widespread, countries such as the United Kingdom have highlighted that a harm minimization approach, rather than an abstinence approach, may be the most appropriate path forward [62]. There have been calls in Australia to shift the sexting conversation, from ones focused predominantly on risk and prevention to one that focuses on ethics, respect, and responsibility [63]. The importance of educating young people about what it means to be an ethical user and consumer of technology is underscored [64]. Ensuring that young people's views are incorporated, and their agency and decision making is respected is important [65], particularly as the voices of young people themselves are often ignored in the development of sexting guidelines and educational responses, despite this being a crucial step in ensuring that such initiatives are appropriate and relevant [66-68].

In line with other research [68], these results emphasize that sexting needs to be positioned within a wider conversation that involves in-depth exploration on topics such as consent, trust, gender, culture, psychological health, body image, and cyberbullying in the context of both technology and social media. Of particular importance relating to this research is sexting's association with suicidal thoughts and behaviors and body image concerns. Currently, the Australian eSafety Commissioner's lesson plans for teachers do not directly discuss with students how psychological and emotional well-being interacts with sexting [69]. Instead, there is greater focus placed on the potential social and legal consequences of sexting. In future, the sexting dialogue could be enriched by acknowledging and supporting young people, and those around them, in understanding and examining ways to address these issues. It should be emphasized that this is not solely engaging in risk-focused conversations but a proactive and in-depth dialogue exploring how young people can look after their own and each other's physical, social, and emotional well-being on the Web. 
The associations between sexting and other variables, including living with parents and late-night internet use, found in this research may demonstrate the important role parents and guardians play. However, parental monitoring of Web-based activities and handling conversations relating to sexting requires care and consideration-particularly as reviews of the digital safety literature [70] suggest that monitoring has the potential to force young people into becoming secretive in their online behaviors if not handled appropriately. Indeed, young people who sexted (two-way and sending) were less likely to endorse keeping a computer in a public room. Overall, a balance between safe sexting and independence needs to be found, and a focus should be placed on arming young people with ICT safety skills, particularly for when they no longer live at home. Both education and the cultivation of open, honest lines of communication with young people are seen as a crucial step in promoting ICT safety [70]. A challenge lies in the fact that research has implicated parents' and teachers' perceived lack of knowledge and skill relating to digital technologies as a barrier to meaningful conversations about sexting with young people [68]. Young people themselves have emphasized that parents also require greater educational support around sexting [68]. In line with previous research [71], providing support to adults so they can feel more confident in guiding young people through their cyber interactions is recommended. Online programs and apps may perform a key role in reducing the harms associated with sexting by empowering young people and adults to have better conversations around safe sexting and digital safety. These apps and electronic tools can be designed for specific groups of people. For example, apps such as the Australian Multicultural Foundation's CyberParent [72] provide culturally and linguistically diverse parents with digital safety tools.

\section{Strengths and Limitations}

There were numerous strengths of the study, which included the surveys comprising large Australia-wide randomly selected stratified samples representative of gender, age groups, and geographical location across 2 time points. The research captured the sociodemographics, mental health, and risk behaviors of young people. Validated measures for psychological distress and suicidal thoughts and behaviors were used, which is often a limitation of sexting research [73]. The sexting surveys captured more in - depth questions relating to the direction (two-way, sending, receiving, and none) and the types of sexts sent (eg, talking about acts of a sexual nature and sending photos or videos showing yourself nude or nearly nude). These factors are especially noteworthy given that previous Australian research has relied on convenience and self-selecting samples and has demonstrated inconsistencies in definitions and the measurement of sexting behaviors $[6,7,11,12]$. Indeed, recent systematic reviews have concluded that the lack of a uniform definition of sexting is a problem that severely limits generalizability between studies [74]; by separating the direction and type of sexting, our research addressed this common concern.
However, the results demonstrated that three-quarters of young Australians had recently engaged in, or been exposed to, some form of sexting activity-which is high when compared with other Australian research $[6,7,11,12]$. This high prevalence rate may be a function of these CATI surveys including numerous sexting items, which is a more inclusive approach compared with single-item measures that comprise both sending and receiving sexts into the 1 variable. When compared with other Australian research, which used convenience samples (conducted at similar time points to these CATIs), this higher sexting prevalence rate may be attributed to a social desirability effect to some extent. Our previous research has shown that items that are more sensitive in nature, such as sexting, are more prone to underreporting in the presence of a telephone interviewer compared with online [75]. It is highly probable that the presence of a face-to-face interviewer in previous research $[6,12]$ may further compound this social desirability effect, whereby respondents may minimize endorsement of embarrassing or unpleasant disclosures to maximize social acceptability and respectability as compared with a telephone interview. Hence, the rates presented in this paper may be a more accurate reflection of sexting prevalence.

Limitations in terms of survey length restricted the number of in - depth questions that could be asked; for example, we did not explore consensual versus nonconsensual sexting. Furthermore, in our examination of reasons for sexting and beliefs about sexting, we analyzed all senders and all receivers of sexts rather than senders only and receivers only - which resulted in a substantial overlap between two-way sexters and senders because of the small sender only sample size (2014, $\mathrm{n}=20$ ). This must be taken into account when interpreting results. When doing so, the results still provide highly useful comparisons between all types of sexting activity (two-way, sender, receiver, and no sexting).

Another research limitation is that we asked about sexting behaviors over the past year; although this is arguably not as problematic as asking respondents to report lifetime sexting, the lengthy period may produce issues with respondent recall. However, as highlighted in previous research [76], shorter periods that gauge current (30 - day) sexting can be problematic as it is an insufficient period to assess the full impact of sexting-such as possible mental health consequences.

\section{Conclusions}

Our research clearly demonstrates that the majority of young Australians sext or are exposed to sexting. Trends over time suggest that the phenomenon of sexting is unlikely to go away. How a young person navigates this brave new world of sexual relationships in this digital landscape is complex, particularly as this research found sexting to be associated with negative health and well-being concerns, including suicidal thoughts and behaviors, body image issues, and cyberbullying. How the community works in partnership with young people to address this in future needs to be a multifaceted approach where sexting is positioned within a wider proactive conversation about gender, culture, psychosocial health, and respecting and caring for each other on the Web. 


\section{Acknowledgments}

This project was carried out through a partnership between the Young and Well CRC (2011-16) and The University of Sydney's BMC, with funding provided by the Young and Well CRC. The authors would like to thank the Youth Mental Health and Technology team at the BMC, with special mention to Hannah Yee.

\section{Conflicts of Interest}

IBH was an inaugural Commissioner on Australia's National Mental Health Commission (2012-18). He is the Co-Director, Health and Policy at the BMC, University of Sydney. The BMC operates an early intervention youth service at Camperdown under contract to headspace. Professor Hickie has previously led community-based and pharmaceutical industry-supported (Wyeth, Eli Lily, Servier, Pfizer, and AstraZeneca) projects focused on the identification and better management of anxiety and depression. He was a member of the medical advisory panel for Medibank Private until October 2017, a Board Member of Psychosis Australia Trust, and a member of Veterans Mental Health Clinical Reference group. He is the Chief Scientific Advisor to, and an equity shareholder in, Innowell. Innowell has been formed by The University of Sydney and PwC to deliver the AUS \$30 million Australian Government-funded Project Synergy. Project Synergy is a 3-year program for the transformation of mental health services through the use of innovative technologies. Professor JMB is Chair of the National Advisory Council for Open Arms, Veterans and Families Counselling Service. She is a well-being and digital health consultant to Bupa, a member of the Veterans Mental Health Clinical Reference group and a Chief Investigator and author of the Defence and Veterans Transition and Wellbeing Study. She is the Founder of, and an equity shareholder in, Innowell. She is Professor of Social Innovation and Chair of the Centre for Mental Health at Swinburne University and Adjunct Professor of Social Impact and Entrepreneurship at RMIT. None of the other authors declare any conflicts of interest.

\section{Multimedia Appendix 1}

Sociodemographic and well-being changes from 2012 to 2014.

[PDF File (Adobe PDF File), 103KB-Multimedia Appendix 1]

\section{Multimedia Appendix 2}

Crude adjusted odds ratios and adjusted odds ratios of the association of demographic, health and well-being items, and internet use with sexting activity (2014 data).

[PDF File (Adobe PDF File), 109KB-Multimedia Appendix 2]

\section{References}

1. Klettke B, Hallford DJ, Mellor DJ. Sexting prevalence and correlates: a systematic literature review. Clin Psychol Rev 2014 Feb;34(1):44-53. [doi: 10.1016/j.cpr.2013.10.007] [Medline: 24370714]

2. Madigan S, Ly A, Rash CL, Van Ouytsel J, Temple JR. Prevalence of multiple forms of sexting behavior among youth: a systematic review and meta-analysis. JAMA Pediatr 2018 Apr 1;172(4):327-335 [FREE Full text] [doi:

10.1001/jamapediatrics.2017.5314] [Medline: 29482215]

3. Levine D. Sexting: a terrifying health risk ... or the new normal for young adults? J Adolesc Health 2013 Mar;52(3):257-258. [doi: 10.1016/j.jadohealth.2013.01.003] [Medline: 23427782]

4. Englander EK. Risky business: talking with your patients about cyberbullying and sexting. Child Adolesc Psychiatr Clin N Am 2018 Dec;27(2):287-305. [doi: 10.1016/j.chc.2017.11.010] [Medline: 29502752]

5. McGovern A, Crofts T, Lee M, Milivojevic S. Media, legal and young people's discourses around sexting. Glob Stud Childhood 2016 Nov 7;6(4):428-441. [doi: 10.1177/2043610616676028]

6. Yeung TH, Horyniak DR, Vella AM, Hellard ME, Lim MS. Prevalence, correlates and attitudes towards sexting among young people in Melbourne, Australia. Sex Health 2014 Sep;11(4):332-339. [doi: 10.1071/SH14032] [Medline: 25087581]

7. Lee M, Crofts T, McGovern A, Milivojevic S. Australian Institute of Criminology. 2015. Sexting among young people: Perceptions and practices URL: https://aic.gov.au/publications/tandi/tandi508 [accessed 2018-10-10] [WebCite Cache ID 733XTaeB2]

8. NSW Department of Justice. 2018 Jun. New legislation to strengthen child sexual abuse laws Factsheet: details URL: https:/ /www.justice.nsw.gov.au/Documents/Media\%20Releases/2018/new-legislation-to-strengthen-child-abuse-laws-details.pdf [accessed 2019-01-08] [WebCite Cache ID 75GPan4RW]

9. Lawrence D, Johnson S, Hafekost J, de Haan KB, Sawyer M, Ainley J, et al. Department of Health. Canberra; 2015. The mental health of children and adolescents: report on the second Australian child and adolescent survey of mental health and wellbeing URL: https://www.health.gov.au/internet/main/publishing.nsf/Content/ 9DA8CA21306FE6EDCA257E2700016945/\%24File/child2.pdf [accessed 2019-05-21] [WebCite Cache ID 77E7qMZDR] 
10. World Health Organization. Geneva; 2020. Mental health action plan 2013-2020 URL: https://apps.who.int/iris/bitstream/ handle/10665/89966/9789241506021 eng.pdf;jsessionid=29F2D21E39095848584C152F7744D660?sequence=1 [accessed 2019-05-21] [WebCite Cache ID 78WhUqRAj]

11. Patrick K, Heywood W, Pitts MK, Mitchell A. Demographic and behavioural correlates of six sexting behaviours among Australian secondary school students. Sex Health 2015 Nov;12(6):480-487. [doi: 10.1071/SH15004] [Medline: 26277625]

12. Lim MS, Vella AM, Horyniak DR, Hellard ME. Exploring attitudes towards sexting of young people: a cross-sectional study. Sex Health 2016 Dec;13(6):530-535. [doi: 10.1071/SH16029] [Medline: 27712613]

13. Lounsbury K, Mitchell K, Finkelhor D. University of New Hampshire. 2011. The True Prevalence of Sexting URL: https:/ /scholars.unh.edu/cgi/viewcontent.cgi?referer=https://scholar.google.com.au/\&httpsredir=1\&article=1063\&context=ccrc [accessed 2018-10-10] [WebCite Cache ID 733WF2nCl]

14. Barrense-Dias Y, Berchtold A, Surís J, Akre C. Sexting and the definition issue. J Adolesc Health 2017 Nov;61(5):544-554. [doi: 10.1016/j.jadohealth.2017.05.009] [Medline: 28734631]

15. Temple JR, Le VD, van den Berg P, Ling Y, Paul JA, Temple BW. Brief report: teen sexting and psychosocial health. J Adolesc 2014 Jan;37(1):33-36 [FREE Full text] [doi: 10.1016/j.adolescence.2013.10.008] [Medline: 24331302]

16. Dake JA, Price JH, Maziarz L, Ward B. Prevalence and correlates of sexting behavior in adolescents. Am J Sex Educ 2012 Jan;7(1):1-15. [doi: 10.1080/15546128.2012.650959]

17. Gordon-Messer D, Bauermeister JA, Grodzinski A, Zimmerman M. Sexting among young adults. J Adolesc Health 2013 Mar;52(3):301-306 [FRE Full text] [doi: 10.1016/j.jadohealth.2012.05.013] [Medline: 23299018]

18. Carrotte ER, Vella AM, Hellard ME, Lim MS. Mental health and associated sexual health behaviours in a sample of young people attending a music festival in Melbourne, Victoria. Community Ment Health J 2016 Dec;52(8):1082-1088. [doi: 10.1007/s10597-015-9981-2] [Medline: 26738496]

19. Temple JR, Choi H. Longitudinal association between teen sexting and sexual behavior. Pediatrics 2014 Nov;134(5):e1287-e1292 [FREE Full text] [doi: 10.1542/peds.2014-1974] [Medline: 25287459]

20. Machimbarrena JM, Calvete E, Fernández-González L, Álvarez-Bardón A, Álvarez-Fernández L, González-Cabrera J. Internet risks: an overview of victimization in cyberbullying, cyber dating abuse, sexting, online grooming and problematic internet use. Int J Environ Res Public Health 2018 Dec 5;15(11) [FREE Full text] [doi: 10.3390/ijerph15112471] [Medline: 30400659]

21. Reyns BW, Burek MW, Henson B, Fisher BS. The unintended consequences of digital technology: exploring the relationship between sexting and cybervictimization. J Crime Just 2013 Mar;36(1):1-17. [doi: 10.1080/0735648x.2011.641816]

22. Delevi R, Weisskirch RS. Personality factors as predictors of sexting. Comput Hum Behav 2013 Nov;29(6):2589-2594. [doi: 10.1016/j.chb.2013.06.003]

23. Crimmins DM, Seigfried-Spellar KC. Peer attachment, sexual experiences, and risky online behaviors as predictors of sexting behaviors among undergraduate students. Comput Hum Behav 2014 Mar;32:268-275. [doi: 10.1016/j.chb.2013.12.012]

24. van Ouytsel J, van Gool E, Walrave M, Ponnet K, Peeters E. Sexting: adolescents' perceptions of the applications used for, motives for, and consequences of sexting. J Youth Stud 2016 Nov:1-25. [doi: 10.1080/13676261.2016.1241865]

25. Clagett B, Nathanson KL, Ciosek SL, McDermoth M, Vaughn DJ, Mitra N, et al. Comparison of address-based sampling and random-digit dialing methods for recruiting young men as controls in a case-control study of testicular cancer susceptibility. Am J Epidemiol 2013 Dec 1;178(11):1638-1647 [FREE Full text] [doi: 10.1093/aje/kwt164] [Medline: 24008901]

26. Kessler RC, Barker PR, Colpe LJ, Epstein JF, Gfroerer JC, Hiripi E, et al. Screening for serious mental illness in the general population. Arch Gen Psychiatry 2003 Feb;60(2):184-189. [Medline: 12578436]

27. Lindelow M, Hardy R, Rodgers B. Development of a scale to measure symptoms of anxiety and depression in the general UK population: the psychiatric symptom frequency scale. J Epidemiol Community Health 1997 Oct;51(5):549-557 [FREE Full text] [Medline: 9425466$]$

28. Sinclair VG, Wallston KA. The development and psychometric evaluation of the Brief Resilient Coping Scale. Assessment 2004 Mar;11(1):94-101. [doi: 10.1177/1073191103258144] [Medline: 14994958]

29. Schuster TL, Kessler RC, Aseltine RH. Supportive interactions, negative interactions, and depressed mood. Am J Community Psychol 1990 Jun;18(3):423-438. [Medline: 2264558]

30. Burns JM, Davenport TA, Durkin LA, Luscombe GM, Hickie IB. The internet as a setting for mental health service utilisation by young people. Med J Aust 2010 Jun 7;192(11 Suppl):S22-S26. [Medline: 20528703]

31. Henderson L. Sexting and sexual relationships among teens and young adults. McNair Scholars Res J 2011;7(1):9 [FREE Full text]

32. IBM. Chicago: IBM; 2015. SPSS Version 22.0 for Windows URL: https://www-01.ibm.com/support/docview. wss?uid=swg27038407 [accessed 2019-05-21] [WebCite Cache ID 78WiTjm73]

33. Australian Bureau of Statistics. 2017. Census: Aboriginal and Torres Strait Islander population URL: http://www.abs.gov.au/ ausstats/abs@.nsf/MediaRealesesByCatalogue/02D50FAA9987D6B7CA25814800087E03?OpenDocument [accessed 2018-10-17] [WebCite Cache ID 73Dv16riD]

34. Weisskirch RS, Delevi R. "Sexting” and adult romantic attachment. Comput Hum Behav 2011 Sep;27(5):1697-1701. [doi: 10.1016/j.chb.2011.02.008] 
35. Döring N. Consensual sexting among adolescents: risk prevention through abstinence education or safer sexting? Cyberpsychology 2014;8(1):e1-16. [doi: 10.5817/CP2014-1-9]

36. Dir AL, Coskunpinar A, Steiner JL, Cyders MA. Understanding differences in sexting behaviors across gender, relationship status, and sexual identity, and the role of expectancies in sexting. Cyberpsychol Behav Soc Netw 2013 Aug;16(8):568-574. [doi: 10.1089/cyber.2012.0545] [Medline: 23675996]

37. Drouin M, Vogel KN, Surbey A, Stills JR. Let's talk about sexting, baby: computer-mediated sexual behaviors among young adults. Comput Hum Behav 2013 Sep;29(5):A25-A30. [doi: 10.1016/j.chb.2012.12.030]

38. Hudson HK. SemanticScholar. Carbondale: Southern Illinois University; 2011. Factors affecting sexting behaviors among selected undergraduate students URL: https://pdfs.semanticscholar.org/82db/961c6ff47693d91f38e0acc324a7fb416565. pdf [accessed 2019-05-21] [WebCite Cache ID 78WjBVfPM]

39. Samimi P, Alderson KG. Sexting among undergraduate students. Comput Hum Behav 2014 Feb;31:230-241. [doi: 10.1016/j.chb.2013.10.027]

40. Lippman JR, Campbell SW. Damned if you do, damned if you don't? if you're a girl: relational and normative contexts of adolescent sexting in the United States. J Child Media 2014 Jun 6;8(4):371-386. [doi: 10.1080/17482798.2014.923009]

41. Ringrose J, Harvey L, Gill R, Livingstone S. Teen girls, sexual double standards and 'sexting': gendered value in digital image exchange. Feminist Theory 2013 Dec;14(3):305-323. [doi: 10.1177/1464700113499853]

42. Walker S, Sanci L, Temple-Smith M. Sexting: young women's and men's views on its nature and origins. J Adolesc Health 2013 Jun;52(6):697-701. [doi: 10.1016/j.jadohealth.2013.01.026] [Medline: 23587784]

43. Rice E, Rhoades H, Winetrobe H, Sanchez M, Montoya J, Plant A, et al. Sexually explicit cell phone messaging associated with sexual risk among adolescents. Pediatrics 2012 Sep 17;130(4):667-673. [doi: 10.1542/peds.2012-0021]

44. Fleschler Peskin M, Markham CM, Addy RC, Shegog R, Thiel M, Tortolero SR. Prevalence and patterns of sexting among ethnic minority urban high school students. Cyberpsychol Behav Soc Netw 2013 Jun;16(6):454-459. [doi:

10.1089/cyber.2012.0452] [Medline: 23438265]

45. Winkelman S, Smith K, Brinkley J, Knox D. Sexting on the College Campus. Electr J Hum Sex 2014;17:e1-15 [FREE Full text]

46. Guilamo-Ramos V, Jaccard J, Dittus P, Bouris A, Holloway I, Casillas E. Adolescent expectancies, parent-adolescent communication and intentions to have sexual intercourse among inner-city, middle school youth. Ann Behav Med 2007 Aug;34(1):56-66. [doi: 10.1007/bf02879921] [Medline: 17688397]

47. Campbell SW, Park YJ. Predictors of mobile sexting among teens: toward a new explanatory framework. Mobile Media Commun 2013 Dec 24;2(1):20-39. [doi: 10.1177/2050157913502645]

48. Medrano JLJ, Lopez Rosales F, Gámez-Guadix M. Assessing the links of sexting, cybervictimization, depression, and suicidal ideation among university students. Arch Suicide Res 2018;22(1):153-164. [doi: 10.1080/13811118.2017.1304304] [Medline: 28287925]

49. Benotsch EG, Snipes DJ, Martin AM, Bull SS. Sexting, substance use, and sexual risk behavior in young adults. J Adolesc Health 2013 Mar;52(3):307-313 [FREE Full text] [doi: 10.1016/j.jadohealth.2012.06.011] [Medline: 23299017]

50. Van Ouytsel J, Walrave M, Ponnet K, Heirman W. The association between adolescent sexting, psychosocial difficulties, and risk behavior: integrative review. J Sch Nurs 2015 Feb;31(1):54-69. [doi: 10.1177/1059840514541964] [Medline: 25027261]

51. Husky MM, Guignard R, Beck F, Michel G. Risk behaviors, suicidal ideation and suicide attempts in a nationally representative French sample. J Affect Disord 2013 Dec;151(3):1059-1065. [doi: 10.1016/j.jad.2013.08.035] [Medline: 24070905]

52. Hallfors DD, Waller MW, Ford CA, Halpern CT, Brodish PH, Iritani B. Adolescent depression and suicide risk: association with sex and drug behavior. Am J Prev Med 2004 Oct;27(3):224-231. [doi: 10.1016/j.amepre.2004.06.001] [Medline: $\underline{15450635]}$

53. Bianchi D, Morelli M, Baiocco R, Chirumbolo A. Psychometric properties of the Sexting Motivations Questionnaire for adolescents and young adults. Rassegna di Psicologia 2018;33(3):5-18 [FREE Full text] [doi: 10.4558/8067-01]

54. Bianchi D, Morelli M, Baiocco R, Chirumbolo A. Sexting as the mirror on the wall: body-esteem attribution, media models, and objectified-body consciousness. J Adolesc 2017;61:164-172 [FREE Full text] [doi: 10.1016/j.adolescence.2017.10.006] [Medline: 29111447]

55. Fredrickson BL, Roberts T. Objectification Theory: toward understanding women's lived experiences and mental health risks. Psychol of Women Q 1997 Jun;21(2):173-206. [doi: 10.1111/j.1471-6402.1997.tb00108.x]

56. Tiggemann M, Slater A. A test of objectification theory in former dancers and non-dancers. Psychol Women Q 2016 Jun 23;25(1):57-64. [doi: 10.1111/1471-6402.00007]

57. Aboujaoude E. Problematic internet use: an overview. World Psychiatry 2010 Jun;9(2):85-90 [FREE Full text] [Medline: 20671890]

58. Gold J. Screen-Smart Parenting: How to Find Balance and Benefit in Your Child's Use of Social Media, Apps, and Digital Devices. New York London: Guilford Publications; 2014.

59. Bellmore A, Calvin AJ, Xu J, Zhu X. The five W?s of ?bullying? on Twitter: who, what, why, where, and when. Comput Hum Behav 2015 Mar;44:305-314. [doi: 10.1016/j.chb.2014.11.052] 
60. Kowalski RM, Giumetti GW, Schroeder AN, Lattanner MR. Bullying in the digital age: a critical review and meta-analysis of cyberbullying research among youth. Psychol Bull 2014 Jul;140(4):1073-1137. [doi: 10.1037/a0035618] [Medline: 24512111]

61. esafety commissioner. 2019. Sexting information for teachers URL: https://www.esafety.gov.au/esafety-information/ esafety-issues/sexting/sexting-information-for-teachers [accessed 2019-10-10] [WebCite Cache ID 77DrFgQ80]

62. Quayle E. Barnardos. Over the Internet, under the Radar: Online Child Sexual Abuse and Exploitation - A Brief Literature Review URL: http://www.barnardos.org.uk/over_the_internet_under_the_radar_literature_review.pdf [accessed 2019-03-29] [WebCite Cache ID 77E8kfS0s]

63. Dobson A, Rasmussen M, Tyson D. Parliament of Victoria. 2013. Submission to the Victorian Law Reform Committee; Inquiry into Sexting URL: https://www.parliament.vic.gov.au/file_uploads/LRC_Sexting_Final_Report_0c0rvqP5.pdf [accessed 2019-05-21] [WebCite Cache ID 77E90SXNI]

64. Harrison T. Virtuous reality: moral theory and research into cyber-bullying. Ethics Inf Technol 2016 Jan 12;17(4):275-283. [doi: $10.1007 / \mathrm{s} 10676-015-9382-9]$

65. Clark M, Lewis A, Bradshaw S, Bradbury-Jones C. How public health nurses' deal with sexting among young people: a qualitative inquiry using the critical incident technique. BMC Public Health 2018 Jun 13;18(1):729 [FREE Full text] [doi: 10.1186/s12889-018-5642-z] [Medline: 29895261]

66. Livingstone S, Mason J. LSE Research Online. London: The European NGO Alliance for Child Safety Online; 2015 . Sexual rights and sexual risks among youth online: a review of existing knowledge regarding children and young people's developing sexuality in relation to new media environments URL: http://eprints.lse.ac.uk/64567/1/

Livingstone Review on Sexual rights and sexual risks among online youth Author 2015.pdf [accessed 2019-05-21] [WebCite Cache ID 77E9MTyd5]

67. Albury K, Crawford K, Byron P, Mathews B. CORE - Aggregating the world's open access research papers. 2013. Young people and sexting in Australiathics, representation and the law URL: https://core.ac.uk/download/pdf/30677128.pdf [accessed 2019-03-29] [WebCite Cache ID 77E9Z9Sfu]

68. Jørgensen CR, Weckesser A, Turner J, Wade A. Young people's views on sexting education and support needs: findings and recommendations from a UK-based study. Sex Educ 2018 Jun 6;19(1):25-40. [doi: 10.1080/14681811.2018.1475283]

69. esafety commisioner. 2019. Standalone lesson plans for secondary classes URL: https://www.esafety.gov.au/ education-resources/classroom-resources/stand-alone-lesson-plans-for-secondary-schools [accessed 2019-03-29] [WebCite Cache ID 77Ds8rxiP]

70. Siegle D. Cyberbullying and sexting: technology abuses of the 21st century. Gifted Child Today 2010 Apr;33(2):14-65. [doi: 10.1177/107621751003300206]

71. Cooper K, Quayle E, Jonsson L, Svedin CG. Adolescents and self-taken sexual images: a review of the literature. Comput Hum Behav 2016 Feb;55:706-716. [doi: 10.1016/j.chb.2015.10.003]

72. Australian Multicultural Foundation. 2018. CyberParent Web App URL: http://www.amf.net.au/entry/cyberparent [accessed 2019-03-29] [WebCite Cache ID 77DsA8onj]

73. Frankel AS, Bass SB, Patterson F, Dai T, Brown D. Sexting, risk behavior, and mental health in adolescents: an examination of 2015 Pennsylvania Youth Risk Behavior Survey data. J Sch Health 2018 Mar;88(3):190-199. [doi: 10.1111/josh.12596] [Medline: 29399839]

74. Englander E, McCoy M. Sexting-prevalence, age, sex, and outcomes. JAMA Pediatr 2018 Apr 1;172(4):317-318. [doi: 10.1001/jamapediatrics.2017.5682] [Medline: 29482201]

75. Milton AC, Ellis LA, Davenport TA, Burns JM, Hickie IB. Comparison of self-reported telephone interviewing and Web-based survey responses: findings from the second Australian Young and Well National Survey. JMIR Ment Health 2017 Sep 26;4(3):e37. [doi: 10.2196/mental.8222] [Medline: 28951382]

76. Mitchell KJ, Finkelhor D, Jones LM, Wolak J. Prevalence and characteristics of youth sexting: a national study. Pediatrics 2012 Jan;129(1):13-20. [doi: 10.1542/peds.2011-1730] [Medline: 22144706]

\section{Abbreviations}

AOR: adjusted odds ratio

BMC: Brain and Mind Centre

CATI: computer-assisted telephone interviewing

CRC: Cooperative Research Centre

ICT: information and communication technology

RDD: random digit dialing 
Edited by J Torous; submitted 08.01.19; peer-reviewed by J Matar, MS Aslam; comments to author 14.02.19; revised version received 31.03.19; accepted 20.04.19; published 17.06.19

Please cite as:

Milton AC, Gill BA, Davenport TA, Dowling M, Burns JM, Hickie IB

Sexting, Web-Based Risks, and Safety in Two Representative National Samples of Young Australians: Prevalence, Perspectives, and Predictors

JMIR Ment Health 2019;6(6):e13338

URL: https://mental.jmir.org/2019/6/e13338/

doi: $10.2196 / 13338$

PMID: 31210139

(C)Alyssa C Milton, Benjamin A Gill, Tracey A Davenport, Mitchell Dowling, Jane M Burns, Ian B Hickie. Originally published in JMIR Mental Health (http://mental.jmir.org), 17.06.2019. This is an open-access article distributed under the terms of the Creative Commons Attribution License (https://creativecommons.org/licenses/by/4.0/), which permits unrestricted use, distribution, and reproduction in any medium, provided the original work, first published in JMIR Mental Health, is properly cited. The complete bibliographic information, a link to the original publication on http://mental.jmir.org/, as well as this copyright and license information must be included. 